\title{
Flavonoid quercetin modulates glucose metabolism by up-regulating the methylation status of genes as Kcnj11, Gys1 and Erp29 in liver of Wistar rats
}

\section{Weina Gao ( gwn2004bo@126.com )}

Tianjin Institute of Environmental and Operational Medicine https://orcid.org/0000-0001-8838-1036

\section{Xiangyu Bian}

Ecole du Val-de-Grace Department of Environmental Preparedness and Operations: Ecole du Val-deGrace Departement de la preparation milieux et operationnelle

\section{Yuying Ma}

Tianjin Institute of Environmental and Operational Medicine

\section{Yijing Yu}

Tianjin Institute of Environmental and Operational Medicine

\section{Tala Shi}

Tianjin Institute of Environmental and Operational Medicine

\section{Zhanxin Yao}

Tianjin Institute of Environmental and Operational Medicine

\section{Lingling Pu}

Tianjin Institute of Environmental and Operational Medcine

\section{Changjiang Guo}

Tianjin Institute of Environmental and Operational Medicine

\section{Research}

Keywords: Quercetin, DNA methylation, epigenetics, Kcnj11, Erp29, Gys1

Posted Date: December 2nd, 2020

DOI: https://doi.org/10.21203/rs.3.rs-118947/v1

License: (c) (1) This work is licensed under a Creative Commons Attribution 4.0 International License. Read Full License 


\section{Abstract}

Background: Quercetin is a flavonoid that exists extensively in vegetables and fruits, and has many biological activities. It is reported that quercetin participates in the regulation of glucose metabolism through various mechanisms. However, whether DNA methylation is involved in those regulatory effects remains unclear. As liver is one of the main organ involved in methyl and glucose metabolism, DNA methylation targets related to glucose metabolism were identified in liver of Wistar rats upon quercetin exposure.

Methods: The rats were fed a control diet or a $0.5 \%$ quercetin-supplemented diet for 6 weeks. Arraystar Rat $4 \times 180 \mathrm{~K}$ RN4 RefSeq Promoter Arrays were used for a genome-wide survey of DNA methylation in rat livers. NimbleScan v2.5 software was used to process microarray data. DAVID software was used to perform GO and Pathway analysis of regulatory networks. Gene promoter methylation status was examined by the ChIP-quantitative PCR assay, and hepatic levels of methylated Kcnj11, Erp29, Gys1, Flot1 and GAPDH were evaluated. Gene expression was assayed by quantitative PCR, and hepatic mRNA expression levels of Kcnj11, Gys1 and Erp29 were estimated.

Results: Quercetin induced specific changes in DNA methylation. A total of 1,263 differentially expressed genes were found in 22 chromosomes, particularly on chromosomes 1, 3, 5, 7, 8, and 10. According to GO functional analysis, differential genes have focused on organic substance, cellular and primary metabolic process. According to pathway analysis, the most enrichment pathways included Type 2 diabetes mellitus, insulin signaling pathway and protein processing in endoplasmic reticulum. Nineteen upmethylated genes were found among several biological pathways after quercetin treatment. Critical genes and pathways associated with glucose metabolism (Kcnj11 and Gys1) and protein processing in the endoplasmic reticulum (Erp29) were changed significantly. Promoter methylation levels of Kcnj11, Gys1, and Erp29 were significantly increased, and the mRNA expression of those genes significantly decreased simultaneously upon quercetin exposure.

Conclusions: Quercetin changed the promoter methylation status and expression of Kcnj11, Gys1, and Erp29, which are mainly related to glucose metabolism. The gene Kcnj11, Gys1, and Erp29 could be novel epigenetic targets of quercetin in regulating glucose metabolism.

\section{Introduction}

Epigenetic changes are heritable changes to gene expression independent of changes to the DNA sequence [1]. DNA methylation is one of important form of epigenetic modification, and generally occurs at the cytosine residue in cytosine-guanine dinucleotide pairs to form 5-methylcytosine [2]. Unlike genetic modifications, epigenetic modulation is reversible and can be altered by certain factors. This characteristic of epigenetic modulation may allow regulation of physiological responses to diet and environmental stimuli $[3,4]$. Evidence has shown that dietary polyphenols present in fruits, vegetables and beverages are potential epigenetic regulators $[5,6]$. It has been reported that the compound quercetin, 
which belongs to the flavonoid subclass of polyphenols, may affect DNA methylation in therapy for cancer and chronic inflammatory disorders $[7,8]$.

Quercetin is a representative compound of flavonoid, and is ubiquitously present in Chinese diet such as fruits and vegetables. Quercetin has been reported to exert a wide range of biological effects, including antioxidant, anticarcinogenic, anti-inflammatory, and combatting gut dysbiosis activities [9-11]. Besides the above properties, quercetin also participates in regulating glucose metabolism. This compound modulates hyperglycemia by improving the pancreatic enzymes activities linked with glucose metabolism in rats with diabetes [12], and alters glucose homeostasis through insulin-dependent and independent mechanism in the brain of diabetic rats [13]. In vitro experiments demonstrated that a mixture containing quercetin had the potential to modulate cellular glucose metabolism in human HepG2 cells [14], and could stimulate insulin release in rat INS-1 beta-cells $[15,16]$. However, whether DNA methylation plays a role in those effects of quercetin is not clear.

The liver plays a pivotal role in controlling glucose metabolism [17]. It can store glucose in the form of glycogen with feeding, assemble glucose via the gluconeogenic pathway in response to fasting, and also participates in metabolizing and releasing glucose [18]. The liver is also an important organ in which quercetin is metabolized to its methylated compounds $[19,20]$. It has been demonstrated that DNA methylation patterns exhibit a tissue specificity across human and mammalian animals [21, 22]. The liver has the highest DNA methylation rate in sika deer [22], while the brain contains the highest levels of DNA methylation in human [23]. Several studies have revealed that DNA methylation plays a much larger role in regulation of tissue-specific expression for genes [24-26]. Otherwise, quercetin improves the ultrastructure of hepatocytes and serum markers of liver injury in diabetic rats [27], and reduces the liver damage induced by drugs [28, 29], chemicals [30-34], and physical factors [35]. As liver is one of the main organ involved in glucose and methyl metabolism, we want to identify DNA methylation targets related to glucose metabolism in liver of rats upon quercetin exposure.

Although nutrition affected global DNA methylation status throughout lifespan in mammalians [36], limited studies have reported how dietary quercetin modulates the tissue specific epigenetic profile. In this study, using rat DNA methylation promoter microarrays, we performed a genome-wide survey of DNA methylation in rat livers exposed to quercetin, and evaluated epigenetic alterations in specific gene promoters by ChIP-quantitative PCR methods. We hypothesized that quercetin would induce the methylations of genes related to glucose metabolism, which could affect gene expression in liver of Wistar rats.

\section{Materials And Methods}

\section{Animals handling}

The animal experiments were approved by the Ethical Committee of the Department of Scientific Management of the Institute. After adaptive feeding with AIN-93M formula [37] for 5 days, 24 Wistar rats were divided randomly into control or $0.5 \%$ quercetin groups according to body weight and maintained on 
an AIN-93 diet (control) or 0.5\% quercetin-supplemented (Sigma-Aldrich, St. Louis, MO, SA) AIN-93 diet $(0.5 \% \mathrm{Q})$ for 6 weeks. Each group consisted of 6 female and 6 male rats, whose initial weights ranged from 180 to $200 \mathrm{~g}$. Dietary intake was recorded daily and body weight weekly. The animal source, handling methods, and environmental conditions matched a previously reported protocol [20]. At the end of the experiment, all rats were fasted overnight. The animals were sacrificed by cervical dislocation. Liver tissues were sampled immediately, washed in ice-cold saline, and frozen in liquid nitrogen until use.

\section{DNA preparation and methylated DNA immunoprecipitation-ChIP analysis}

Liver samples from 2 female and 2 male rats in each group were randomly selected for genome-wide methylation analysis. Genomic DNA (gDNA) extraction, purification, quantification, and quality assessments were conducted according to the procedure of Aksomics, Ltd. (Shanghai, China). Sonicated gDNA was used for immunoprecipitation with a mouse monoclonal anti-5-methylcytosine antibody (Diagenode, Liège, Belgium). Methylated DNA immunoprecipitation DNA (MeDIP DNA) was purified and quantified using Qiagen MinElute columns (Qiagen, Hilden, Germany) and a nanodrop ND-1000 spectrophotometer (Thermo Fisher Scientific, Waltham, MA, USA). A NimbleGen Dual-Color DNA Labeling Kit was used for DNA labeling according to the NimbleGen MeDIP-chip protocol (Nimblegen Systems, Inc., Madison, WI, USA). The microarrays were then hybridized with Cy3/5- labelled DNA and washed using the Nimblegen Wash Buffer Kit (Nimblegen Systems, Inc).

The Arraystar Rat $4 \times 180 \mathrm{~K}$ RN4 RefSeq Promoter Array (Aksomics, Shanghai, China) is designed to investigate DNA methylation and transcription factor binding sites within RefSeq Gene promoter regions and includes 15,987 gene promoter regions (from about -1300 bp to +500 bp of the transcript start sequences) covered by approximately 180,000 probes with approximately 158 bp spacing.

\section{Data Normalization and Analysis}

The MeDIP-chip data were analyzed by sliding-window (1500 bp) peak-finding algorithm provided by NimbleScan v2.5 (Roche-NimbleGen Inc.) from the normalized log2 ratio data. NimbleScan detects peaks by searching for at least two probes above a p-value minimum cutoff $(-\log 10)$ of 2 and maximum spacing of $500 \mathrm{bp}$ between nearby probes within the peaks. To compare differentially enriched regions between the $0.5 \% \mathrm{Q}$ group and the control group, the log2 ratios were averaged and then used to calculate

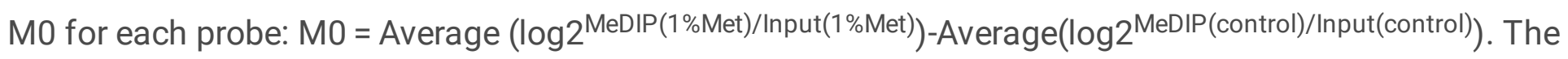
NimbleScan sliding-window peak-finding algorithm was run on these data to find the differential enrichment peaks (DEPs). The DEPs, identified by the NimbleScan algorithm, were filtered according to the following criteria: (1) At least one of the two groups has a median log2 MeDIP/Input $\geq 0.3$ and a median $M 0>0$. (2) At least half of the probes in a peak may have a $C V \leq 0.8$ in both groups. To separate strong $\mathrm{CpG}$ islands from weak $\mathrm{CpG}$ islands, promoters were categorized into three levels: high CpG promoters/regions ( $\mathrm{HCP}$, high $\mathrm{CpG}$ density promoter), intermediate $\mathrm{CpG}$ promoters/regions (ICP, intermediate $\mathrm{CpG}$ density promoter), and low CpG promoters/regions (LCP, low CpG density promoter).

\section{Microarray data processing and Gene Ontology (GO) and Pathway analysis}


Raw microarray data were normalized by the Bioconductor packages Ringo, limma, and MEDME. Normalized MeDIP-chip data were analyzed by NimbleScan v2.5 (NimbleGen). DAVID software was used to perform GO and Pathway analysis of regulatory networks. The GO project provides a controlled vocabulary to describe gene and gene product attributes in any organism and covers three domains: Biological Process, Cellular Component and Molecular Function. Pathway analysis is functional analysis that maps genes to KEGG pathways. The p-value (EASE-score, Fisher-Pvalue or Hypergeometric-Pvalue) denotes the significance of the Pathway correlated to the conditions. Lower the $p$-value, more significant is the Pathway (The recommend p-value cut-off is 0.05 ), using an unbiased, automated survey of published scientific literature (Global Literature Analysis). This analysis identifies functional relations among genes, such as direct binding, up-regulation or down-regulation and also builds subnetworks of genes and cellular processes based on their interconnections.

\section{ChIP-quantitative PCR assay}

A MeDIP assay combined with real-time quantitative PCR (qPCR) was used to evaluate the methylation status of candidate genes in the rat liver. MeDIP was performed as described above. Quantitative PCR was used to analyze the expression of purified DNA with an Applied Biosystems 7900 Real-Time PCR System (Applied Biosystems, Foster City, CA, USA). Expression levels of methylated Flot1, Kcnj11, Gys1, Erp29, and GAPDH were evaluated. The primers used for ChIP validation are shown in Table 1.

Table 1

Sequences of the primers used in qChIP analyses

\begin{tabular}{|lll|}
\hline Genes & Primer sequence & Product length (bp) \\
\hline Flot1 & F:5' GGCGACTCGACCTCTTGCT 3' & 104 \\
& R:5' CGTGCGTCCGAACACTTCT 3' & \\
\hline Kcnj11 & F:5' TGTGCCCCGGATTTCCCAT 3' & 121 \\
& R:5' GGTTGCAGGGTGACTCGAAGG 3' & \\
\hline Gys1 & F:5' TCCCGGTCATCCAGTCATCT 3' & 106 \\
& R:5' CACCCGCTTTCCAATTTAGC 3' & \\
Erp29 & F:5' GCTATGATCCCTGTGTCTTCTCCAG 3' & 56 \\
& R:5' GTGATAAAGGCTCGAAGGAATGAA 3' & \\
\hline GAPDH & F:5'GGACCCTGTGGTGCTTCATCT3' & 181 \\
& R:5'GGGCAGTAAGTGCTCCTAATCG3' & \\
\hline
\end{tabular}

\section{Quantitative PCR analysis}


Hepatic mRNA expressions of genes were determined by quantitative PCR (qPCR) [38]. Total hepatic RNA was isolated using the TRIzol reagent. The first CDNA strand was synthesized using a CDNA synthesis kit. Quantitative PCR was performed using a FastStart Universal SYBR Green Master Mix kit. TRIzol reagent, cDNA synthesis kit, and FastStart Universal SYBR Green Master Mix kit were purchased from Roche, Ltd. (Basel, Switzerland). Finally, melting curve analysis was performed by slowly cooling the PCR mixture with simultaneous measurement of the SYBR Green I signal intensity using an ABI Real-time PCR System (Applied Biosystems). The $\Delta$ threshold cycle (Ct) method was used to evaluate relative quantification, and GAPDH was used as a reference. The primers used for qPCR validation are shown in Table 2.

Table 2

Sequences of the primers used in qPCR analyses

\begin{tabular}{|lll|}
\hline Genes & Primers sequence & Product length (bp) \\
\hline Erp29 & F:5' GACAAGAAGTGGGCCAGTCA 3' & 168 \\
& R :5' GAAGGCGGTGAGGATGTTGA 3' & \\
Kcnj11 & F: 5' GTCAGGGGCTCAGTAAGCAA 3' & 105 \\
& R :5' CTTGCACCAACCTCTGGACT 3' \\
Gys1 & F:5' GAGGGCAGAATGTCGGTCAA 3' & 172 \\
& R :5' GTACACGTGGGGCTTCAAGA 3' \\
\hline GAPDH & F: 5'CCCCCAATGTATCCGTTGTG 3' & 192 \\
& R :5'TAGCCCAGGATGCCCTTTAGT 3' & \\
\hline
\end{tabular}

\section{Statistical analysis}

The one-sided Kolmogorov-Smirnov test was applied to analyze the microarray data. Fisher's exact test was used to perform GO and Pathway analysis. ChIP-quantitative PCR and qPCR data are presented as means \pm standard deviation. Statistical analysis was performed using the SPSS 10.01 software (SPSS Inc., Chicago, IL, USA). Student's t-test was used to compare differences between two groups. Differences between two groups were considered statistically significant at $p<0.05$.

\section{Results}

Quercetin does not change body weight or dietary intake

No significant difference was found in body weight or food intake between the control and quercetin groups (Fig. 1).

Quercetin alters DNA methylation markers of genes involved in biological process 
Genome-wide DNA methylation analysis indicated that quercetin induced specific changes in DNA methylation. A total of 1,263 differentially methylated promoters (DMRs) were found in 22 chromosomes (Fig. 2), particularly on chromosomes 1, 3, 5, 7, 8, and 10. Among these DMRs, 670 (53.05\%) were located in high CpG density promoters (HCP), 309 (24.47\%) in intermediate $\mathrm{CpG}$ density promoters (ICP), and 284 (22.49) in low CpG density promoters (LCP) (Fig. 2). Nine hundred twenty one hypermethylated DMRs (72.92\%) and 342 hypomethylated DMRs (37.08\%) were found in the $0.5 \%$ quercetin group compared with the DMRs of the control group.

In the up regulation of $\mathrm{GO}$ biological process, differential genes have focused on cellular metabolic process and primary metabolic process (Fig. 3). In the down regulation of $\mathrm{GO}$ biological process, differential genes have focused on organic substance, cellular and primary metabolic process (Fig. 4). By pathway analysis of up regulation, the most enrichment pathways included Type 2 diabetes mellitus, insulin signaling pathway and protein processing in endoplasmic reticulum (Fig. 5).

\section{Quercetin alters promoter methylation of specific genes in biological pathways}

When Peak Score was set at $\geq 3$, Peak Length $\geq 500$, and Peak $M$ value higher than the median, we found that the promoters methylation status of 169 genes was changed by quercetin treatment, including 35 down-methylated genes and 134 up-methylaed genes. When those 169 genes were screened against genes in differential biological pathways, 19 up-methylated genes were identified after quercetin treatment (Table 3). Five of the genes are associated with insulin and its signaling pathway, including Kcnj11 in type 2 diabetes mellitus, and Irs2, Flot1, Gys1, and Foxo1 in the insulin signaling pathway. Erp29 is involved in protein processing in the endoplasmic reticulum. 
Table 3

Differential genes in biological pathways

\begin{tabular}{|c|c|c|c|}
\hline Gene & $\begin{array}{l}\text { Promoter } \\
\text { Classification }\end{array}$ & $\begin{array}{l}\text { Peak score } \\
(0.5 \% Q \text { group vs } \\
\text { control) }\end{array}$ & Pathways \\
\hline Tnni3 & LCP & 3.85 & Adrenergic signaling in cardiomyocytes \\
\hline Sstr2 & ICP & 3.51 & Neuroactive ligand-receptor interaction \\
\hline Slc6a3 & ICP & 3.16 & Dopaminergic synapse \\
\hline Rrm2b & $\mathrm{HCP}$ & 3.42 & Purine metabolism \\
\hline \multirow[t]{3}{*}{ Ptpn6 } & LCP & 4.01 & Proteoglycans in cancer \\
\hline & & & B cell receptor signaling pathway \\
\hline & & & T cell receptor signaling pathway \\
\hline Polr2c & $\mathrm{HCP}$ & 3.14 & Purine metabolism \\
\hline Orai3 & LCP & 3.03 & Calcium signaling pathway \\
\hline Mrvi1 & LCP & 4.08 & Vascular smooth muscle contraction \\
\hline Kcnj11 & $\mathrm{HCP}$ & 3.37 & Type 2 diabetes mellitus \\
\hline \multirow[t]{2}{*}{ Irs2 } & $\mathrm{HCP}$ & 3.39 & Insulin signaling pathway \\
\hline & & & FoxO signaling pathway \\
\hline \multirow[t]{2}{*}{ Gys1 } & $\mathrm{HCP}$ & 3.96 & PI3K-Akt signaling pathway \\
\hline & & & Insulin signaling pathway \\
\hline Gpr35 & LCP & 3.55 & Neuroactive ligand-receptor interaction \\
\hline Gpc3 & $\mathrm{HCP}$ & 3.77 & Proteoglycans in cancer \\
\hline \multirow[t]{5}{*}{ Foxo1 } & $\mathrm{HCP}$ & 3.44 & Thyroid hormone signaling pathway \\
\hline & & & Insulin signaling pathway \\
\hline & & & Prostate cancer \\
\hline & & & FoxO signaling pathway \\
\hline & & & Pathways in cancer \\
\hline Flot1 & ICP & 3.05 & Insulin signaling pathway \\
\hline
\end{tabular}

Abbreviation: HCP: high $\mathrm{CpG}$ density promoter; ICP: intermediate $\mathrm{CpG}$ density promoter; LCP: low CpG density promoter 


\begin{tabular}{|llll|}
\hline Gene & $\begin{array}{l}\text { Promoter } \\
\text { Classification }\end{array}$ & $\begin{array}{l}\text { Peak score } \\
(\mathbf{0 . 5 \% Q} \text { group vs } \\
\text { Control) }\end{array}$ & Pathways \\
\hline Erp29 & HCP & 3.96 & $\begin{array}{l}\text { Protein processing in endoplasmic } \\
\text { reticulum }\end{array}$ \\
\hline Dolk & HCP & 3.88 & N-Glycan biosynthesis \\
\hline Bid & ICP & 3.44 & Apoptosis \\
\hline Aqp3 & HCP & 3.54 & Pathways in cancer \\
\hline $\begin{array}{l}\text { Abbreviation: HCP: high } \text { CpG density promoter; ICP: intermediate CpG density promoter; LCP: low CpG } \\
\text { density promoter }\end{array}$ & $\begin{array}{l}\text { Vasopressin-regulated water } \\
\text { reabsorption }\end{array}$ \\
\hline
\end{tabular}

\section{Quercetin increases methylation levels and decreases mRNA expression of Erp29, Gys1, and Kcnj11}

The promoter methylation levels of Kcnj11, Gys1, and Erp29 were significantly increased in the $0.5 \%$ quercetin group (Fig. 6), whereas the mRNA expression of those genes was notably decreased (Fig. 7). No difference was found in methylation status of the genes coding for Flot1 (Fig. 6).

\section{Discussion}

Our genome-wide analysis of the DNA methylation landscape in rats revealed that some genes were changed significantly by quercetin. According to GO functional analysis, differential genes have focused on organic substance, cellular and primary metabolic process. According to pathway analysis, the most enrichment pathways of Type 2 diabetes mellitus, insulin signaling pathway and protein processing in endoplasmic reticulum were changed by quercetin. Differentially methylated $\mathrm{CpG}$ sites were upmethylated in response to quercetin. Those sites were mainly located in genes involved in insulin metabolism, including Kcnj11, Irs2, Gys1, Flot1, and Foxo1. These results suggest that quercetin may regulate peptide hormone metabolism, especially insulin metabolism, by epigenetic mechanisms.

In the present study, we found for the first time that Kcnj11, Gys1, and Erp29 were significantly upmethylated, while their mRNA expression levels were down-regulated in rat livers. Kcnj11, the potassium inwardly-rectifying channel, subfamily J, member 11 gene, encodes Kir6.2, a subunit of ATP-sensitive potassium $\left(\mathrm{K}_{\text {ATP }}\right.$ ) channels in mammalian cells. In pancreatic beta cells, $\mathrm{K}_{\text {ATP }}$ channels play a pivotal role in glucose-stimulated insulin secretion [39-41]. It has been reported that Kcnj11 gene methylation might be associated with type 2 diabetes mellitus (T2DM). In patients with T2DM, one or more locus of the Kcnj11 gene was significantly up-methylated, and this alteration may mimic genetic defects [42, 43]. However, experiments in vitro got different results. Insulin secretion was continuously increased in 
Kir6. $2^{-/-}$beta cells under unstimulated conditions [44]. Increased insulin secretion was also observed in cultured islets isolated from Kir6. $2^{-/-}$mice [45]. In vivo experiments confirmed that the hyperinsulinemic phenotype was based on incomplete loss of $\mathrm{K}_{\text {ATP }}$ in beta cells [46]. For example, methylation at a specific locus of the Kcnj11 gene reduced expression of the Kir6.2 subunit. In our experiment, we found that hepatic Kcnj11 was up-methylated and its mRNA expression down-regulated after quercetin treatment, indicating that Kcnj11 expression was incompletely lost, which might account for the hyperinsulinemic phenotype. Actually, quercetin stimulated insulin release in rat INS-1 beta-cells [15, 16], and transient $\mathrm{K}_{\text {ATP }}$ channel inhibition induced by DNA methylation may be one of the mechanisms.

The Erp29 gene encodes endoplasmic reticulum protein 29 (ERp29). ERp29 is a molecular chaperone that plays a pivotal role in protein secretion, folding, and trafficking. ERp29 is highly expressed in secretory tissues, including in the pancreas and liver [47]. High ERp29 protein expression was found in islets of transgenic MKR mice, and was associated with T2DM development [48]. Our results show that quercetin epigenetically down-regulates Erp29 expression in the rat liver. Therefore, we inferred that the Erp29 gene may be an important target of quercetin in preventing T2DM development. The Gys1 gene encodes glycogen synthase, which catalyzes the key step of glycogen synthesis in liver and muscle cells $[49,50]$. Under fasting conditions, lower glycemia and higher insulinemia were found in Gys1-knockout mice. However, under normal conditions, the mice showed no abnormalities in glucose tolerance, insulin secretion, or basal glycemia [51]. In our research, we found that the Gys1 gene was epigenetically downregulated in healthy rats upon quercetin treatment. Considering the results from Gys1-knockout mice, we speculate that the effects of quercetin on the Gys1 gene may not cause adverse effects to healthy rats.

\section{Conclusions}

In the present study, we showed that quercetin is involved in the regulation of glucose metabolism by regulating the methylation level of Kcnj11, Gys1, and Erp29 genes, and also modulating related glucose metabolism pathways. Quercetin may be helpful to maintain the balance of blood glucose, and consumption of functional food and nutraceutical rich in quercetin could be a cheap and affordable method for the improvement of hyperglycemia.

We reported for the first time that the effects of quercetin on methylation status of genes participating in the glucose metabolism in Wistar rats. To our knowledge, intervention studies of dietary factors on DNA methylation patterns in humans are very limited besides the study on folic acid [52]. Our results will provide a reference for future studies that examining the interplay of epigenetics and environmental factors in humans.

\section{Abbreviations}

gDNA: Genomic DNA; MeDIP DNA: methylated DNA immunoprecipitation DNA; GO: Gene Ontology; qPCR: real-time quantitative PCR; DMRs: differentially methylated promoters; HCP: high $\mathrm{CpG}$ density promoters; 
ICP: intermediate CpG density promoters; LCP: low CpG density promoters; KATP channels: ATP-sensitive potassium channels; T2DM: type 2 diabetes mellitus; ERp29: endoplasmic reticulum protein 29.

\section{Declarations}

\section{Acknowledgements}

The authors thank Zongkai Xie for his help in Animals handling; the authors also want to thank Xiu Jin and Lingling Wang for their help in performing the experiments.

\section{Funding}

The author(s) disclosed receipt of the following financial support for the research, authorship, and/or publication of this article: This work was supported by the National Natural Science Foundation of China (Grant No. 81372988, 81602842, 81172656).

\section{Availability of data and materials}

All data generated or analyzed during this study are included in the article and its supplementary information files.

\section{Competing interests}

The authors declare that they have no competing interests.

\section{Consent for publication}

Not applicable. .

\section{Authors' contributions}

WG, LP, YM, YY, TS and ZY designed and performed the experiments, $X B$ analyzed the data. WG, LP, and CG drafted and reviewed the article. All authors revised and approved the final version of the article. The authors have declared no conflict of interest.

\section{Authors' information}

Department of Nutrition, Tianjin Institute of Environmental and Operational Medicine, Tianjin 300050, People's Republic of China

\section{References}

1. Deans C, Maggert KA. What do you mean, "epigenetic"? Genetics. 2015; 199(4): 887-96. https://doi.org/10.1534/genetics.114.173492. 
2. Issa JP, Kantarjian HM. Targeting DNA methylation. Clin Cancer Res. 2009; 15(12): 3938-46. https://doi.org/10.1158/1078-0432.Ccr-08-2783.

3. Jaenisch R, Bird A. Epigenetic regulation of gene expression: how the genome integrates intrinsic and environmental signals. Nat Genet. 2003; 33 Suppl:245-54. https://doi.org/10.1038/ng1089.

4. Kader F, Ghai M, Maharaj L. The effects of DNA methylation on human psychology. Behav Brain Res. 2018; 346:47-65. https://doi.org/10.1016/j.bbr.2017.12.004.

5. Thakur VS, Deb G, Babcook MA, Gupta S. Plant phytochemicals as epigenetic modulators: role in cancer chemoprevention. Aaps J. 2014; 16(1): 151-63. https://doi.org/10.1208/s12248-013-9548-5.

6. Russo GL, Vastolo V, Ciccarelli M, Albano L, Macchia PE, Ungaro P. Dietary polyphenols and chromatin remodeling. Crit Rev Food Sci Nutr. 2017; 57(12): 2589-99. https://doi.org/10.1080/10408398.2015.1062353.

7. Meeran SM, Ahmed A, Tollefsbol TO. Epigenetic targets of bioactive dietary components for cancer prevention and therapy. Clin Epigenetics. 2010; 1(3-4): 101-16. https://doi.org/10.1007/s13148-0100011-5.

8. Szarc vel Szic K, Ndlovu MN, Haegeman G, Vanden Berghe W. Nature or nurture: let food be your epigenetic medicine in chronic inflammatory disorders. Biochem Pharmacol. 2010; 80(12): 1816-32. https://doi.org/10.1016/j.bcp.2010.07.029.

9. Carullo G, Cappello AR, Frattaruolo L, Badolato M, Armentano B, Aiello F. Quercetin and derivatives: useful tools in inflammation and pain management. Future Med Chem. 2017; 9(1): 79-93. https://doi.org/10.4155/fmc-2016-0186.

10. Carullo G, Perri M, Manetti F, Aiello F, Caroleo MC, Cione E. Quercetin-3-oleoyl derivatives as new GPR40 agonists: Molecular docking studies and functional evaluation. Bioorg Med Chem Lett. 2019; 29(14): 1761-64. https://doi.org/10.1016/j.bmcl.2019.05.018.

11. Shi T, Bian X, Yao Z, Wang Y, Gao W, Guo C. Quercetin improves gut dysbiosis in antibiotic-treated mice. Food Funct. 2020; 11(9): 8003-13. https://doi.org/10.1039/d0fo01439g.

12. Oyedemi SO, Nwaogu G, Chukwuma Cl, Adeyemi OT, Matsabisa MG, Swain SS, et al. Quercetin modulates hyperglycemia by improving the pancreatic antioxidant status and enzymes activities linked with glucose metabolism in type 2 diabetes model of rats: In silico studies of molecular interaction of quercetin with hexokinase and catalase. J Food Biochem. 2020; 44(2): e13127. https://doi.org/10.1111/jfbc.13127.

13. M SS, C DN. Influence of quercetin, naringenin and berberine on glucose transporters and insulin signalling molecules in brain of streptozotocin-induced diabetic rats. Biomed Pharmacother. 2017; 94:605-11. https://doi.org/10.1016/j.biopha.2017.07.142.

14. Kerimi A, Jailani F, Williamson G. Modulation of cellular glucose metabolism in human HepG2 cells by combinations of structurally related flavonoids. Mol Nutr Food Res. 2015; 59(5): 894-906. https://doi.org/10.1002/mnfr.201400850.

15. Kittl M, Beyreis M, Tumurkhuu M, Fürst J, Helm K, Pitschmann A et al. Quercetin Stimulates Insulin Secretion and Reduces the Viability of Rat INS-1 Beta-Cells. Cell Physiol Biochem. 2016; 39(1): 278- 
93. https://doi.org/10.1159/000445623.

16. Youl E, Bardy G, Magous R, Cros G, Sejalon F, Virsolvy A, et al. Quercetin potentiates insulin secretion and protects INS-1 pancreatic $\beta$-cells against oxidative damage via the ERK $1 / 2$ pathway. $\mathrm{Br} \mathrm{J}$ Pharmacol. 2010; 161(4): 799-814. https://doi.org/10.1111/j.1476-5381.2010.00910.x.

17. Han HS, Kang G, Kim JS, Choi BH, Koo SH. Regulation of glucose metabolism from a liver-centric perspective. Exp Mol Med. 2016; 48(3): e218. https://doi.org/10.1038/emm.2015.122.

18. Trefts E, Gannon M, Wasserman DH. The liver. Curr Biol. 2017; 27(21): R1147-R1151. https://doi.org/10.1016/j.cub.2017.09.019.

19. Egert S, Wolffram S, Bosy-Westphal A, Boesch-Saadatmandi C, Wagner AE, Frank J, et al. Daily quercetin supplementation dose-dependently increases plasma quercetin concentrations in healthy humans. J Nutr. 2008; 138(9): 1615-21. https://doi.org/10.1093/jn/138.9.1615.

20. Gao W, Pu L, Chen M, Wei J, Xin Z, Wang Y, et al. Glutathione homeostasis is significantly altered by quercetin via the Keap1/Nrf2 and MAPK signaling pathways in rats. J Clin Biochem Nutr. 2018; 62(1): 56-62. https://doi.org/10.3164/jcbn.17-40.

21. Zhou J, Sears RL, Xing X, Zhang B, Li D, Rockweiler NB, et al. Tissue-specific DNA methylation is conserved across human, mouse, and rat, and driven by primary sequence conservation. BMC Genomics. 2017; 18(1): 724. https://doi.org/10.1186/s12864-017-4115-6.

22. Yang C, Zhang Y, Liu W, Lu X, Li C. Genome-wide analysis of DNA methylation in five tissues of sika deer (Cervus nippon). Gene. 2018; 645:48-54. https://doi.org/10.1016/j.gene.2017.12.032.

23. Ehrlich M, Gama-Sosa MA, Huang LH, Midgett RM, Kuo KC, McCune RA, et al. Amount and distribution of 5-methylcytosine in human DNA from different types of tissues of cells. Nucleic Acids Res. 1982; 10(8): 2709-2721. https://doi.org/10.1093/nar/10.8.2709.

24. Lee HJ, Lowdon RF, Maricque B, Zhang B, Stevens M, Li D, et al. Developmental enhancers revealed by extensive DNA methylome maps of zebrafish early embryos. Nat Commun. 2015; 6:6315. https://doi.org/10.1038/ncomms7315.

25. Lowdon RF, Zhang B, Bilenky M, Mauro T, Li D, Gascard P et al. Regulatory network decoded from epigenomes of surface ectoderm-derived cell types. Nat Commun. 2014; 5:5442. https://doi.org/10.1038/ncomms6442.

26. Zhang B, Zhou Y, Lin N, Lowdon RF, Hong C, Nagarajan RP, et al. Functional DNA methylation differences between tissues, cell types, and across individuals discovered using the M\&M algorithm. Genome Res. 2013; 23(9): 1522-40. https://doi.org/10.1101/gr.156539.113.

27. Maksymchuk O, Shysh A, Rosohatska I, Chashchyn M. Quercetin prevents type 1 diabetic liver damage through inhibition of CYP2E1. Pharmacol Rep. 2017; 69(6): 1386-92. https://doi.org/10.1016/j.pharep.2017.05.020.

28. Taslidere E, Dogan Z, Elbe H, Vardi N, Cetin A, Turkoz Y. Quercetin protection against ciprofloxacin induced liver damage in rats. Biotech Histochem. 2016; 91(2): 116-121. https://doi.org/10.3109/10520295.2015.1085093. 
29. Kocahan S, Dogan Z, Erdemli E, Taskin E. Protective Effect of Quercetin Against Oxidative Stressinduced Toxicity Associated With Doxorubicin and Cyclophosphamide in Rat Kidney and Liver Tissue. Iran J Kidney Dis. 2017; 11(2): 124-31.

30. Ince $\mathrm{E}$. The protective effect of quercetin in the alcohol-induced liver and lymphoid tissue injuries in newborns. Mol Biol Rep. 2020; 47(1): 451-59. https://doi.org/10.1007/s11033-019-05148-0.

31. Rocha de Oliveira C, Ceolin J, Rocha de Oliveira R, Gonçalves Schemitt E, Raskopf Colares J, De Freitas Bauermann $L$ et al. Effects of quercetin on polychlorinated biphenyls-induced liver injury in rats. Nutr Hosp. 2014; 29(5): 1141-48. https://doi.org/10.3305/nh.2014.29.5.7362.

32. Kalantari H, Foruozandeh H, Khodayar MJ, Siahpoosh A, Saki N, Kheradmand P. Antioxidant and hepatoprotective effects of Capparis spinosa L. fractions and Quercetin on tert-butyl hydroperoxideinduced acute liver damage in mice. J Tradit Complement Med. 2018; 8(1): 120-27. https://doi.org/10.1016/j.jtcme.2017.04.010.

33. Zou W, Liu W, Yang B, Wu L, Yang J, Zou T et al. Quercetin protects against perfluorooctanoic acidinduced liver injury by attenuating oxidative stress and inflammatory response in mice. Int Immunopharmacol. 2015; 28(1): 129-35. https://doi.org/10.1016/j.intimp.2015.05.043.

34. Ghosh A, Mandal AK, Sarkar S, Das N. Hepatoprotective and neuroprotective activity of liposomal quercetin in combating chronic arsenic induced oxidative damage in liver and brain of rats. Drug Deliv. 2011; 18(6): 451-459. https://doi.org/10.3109/10717544.2011.577110.

35. Duan X, Chen P, Han X, Ren J, Wang Z, Zhao G, et al. The influence of liposomal quercetin on liver damage induced by microwave ablation. Sci Rep. 2017; 7(1): 12677. https://doi.org/10.1038/s41598-017-13010-1.

36. Guarasci F, D'Aquila P, Mandalà M, Garasto S, Lattanzio F, Corsonello A et al. Aging and nutrition induce tissue-specific changes on global DNA methylation status in rats. Mech Ageing Dev. 2018; 174:47-54. https://doi.org/10.1016/j.mad.2018.02.001.

37. Reeves PG, Nielsen FH, Fahey GC, Jr. AIN-93 purified diets for laboratory rodents: final report of the American Institute of Nutrition ad hoc writing committee on the reformulation of the AIN-76A rodent diet. J Nutr. 1993; 123(11): 1939-51. https://doi.org/10.1093/jn/123.11.1939.

38. Zhang M, Xie Z, Gao W, Pu L, Wei J, Guo C. Quercetin regulates hepatic cholesterol metabolism by promoting cholesterol-to-bile acid conversion and cholesterol efflux in rats. Nutr Res. 2016; 36(3): 271-79. https://doi.org/10.1016/j.nutres.2015.11.019.

39. Thomas PM, Cote GJ, Wohllk N, Haddad B, Mathew PM, Rabl W et al. Mutations in the sulfonylurea receptor gene in familial persistent hyperinsulinemic hypoglycemia of infancy. Science. 1995; 268(5209): 426-29. https://doi.org/10.1126/science.7716548.

40. Thomas $P, Y e Y$, Lightner E. Mutation of the pancreatic islet inward rectifier Kir6.2 also leads to familial persistent hyperinsulinemic hypoglycemia of infancy. Hum Mol Genet. 1996; 5(11): 1809-12. https://doi.org/10.1093/hmg/5.11.1809.

41. Ashcroft FM. ATP-sensitive potassium channelopathies: focus on insulin secretion. J Clin Invest. 2005; 115(8): 2047-58. https://doi.org/10.1172/jci25495. 
42. Liu L, Nagashima K, Yasuda T, Liu Y, Hu HR, He G, et al. Mutations in KCNJ11 are associated with the development of autosomal dominant, early-onset type 2 diabetes. Diabetologia. 2013; 56(12): 260918. https://doi.org/10.1007/s00125-013-3031-9.

43. van Otterdijk SD, Binder AM, Szarc Vel Szic K, Schwald J, Michels KB. DNA methylation of candidate genes in peripheral blood from patients with type 2 diabetes or the metabolic syndrome. PLoS One. 2017; 12(7): e0180955. https://doi.org/10.1371/journal.pone.0180955.

44. Miki T, Nagashima K, Tashiro F, Kotake K, Yoshitomi H, Tamamoto A, et al. Defective insulin secretion and enhanced insulin action in KATP channel-deficient mice. Proc Natl Acad Sci U S A. 1998; 95(18): 10402-6. https://doi.org/10.1073/pnas.95.18.10402.

45. Kawaki J, Nagashima K, Tanaka J, Miki T, Miyazaki M, Gonoi T, et al. Unresponsiveness to glibenclamide during chronic treatment induced by reduction of ATP-sensitive K+ channel activity. Diabetes. 1999; 48(10): 2001-2006. https://doi.org/10.2337/diabetes.48.10.2001.

46. Remedi MS, Rocheleau JV, Tong A, Patton BL, McDaniel ML, Piston DW, et al. Hyperinsulinism in mice with heterozygous loss of K(ATP) channels. Diabetologia. 2006; 49(10): 2368-78. https://doi.org/10.1007/s00125-006-0367-4.

47. Sargsyan E, Baryshev M, Backlund M, Sharipo A, Mkrtchian S. Genomic organization and promoter characterization of the gene encoding a putative endoplasmic reticulum chaperone, ERp29. Gene. 2002; 285(1-2): 127-39. https://doi.org/10.1016/s0378-1119(02)00417-1.

48. Lu H, Yang Y, Allister EM, Wijesekara N, Wheeler MB. The identification of potential factors associated with the development of type 2 diabetes: a quantitative proteomics approach. Mol Cell Proteomics. 2008; 7(8): 1434-51. https://doi.org/10.1074/mcp.M700478-MCP200.

49. Zuo B, Xiong YZ, Deng CY, Su YH, Wang J, Lei MG, et al. Polymorphism, linkage mapping and expression pattern of the porcine skeletal muscle glycogen synthase (GYS1) gene. Anim Genet. 2005; 36(3): 254-7. https://doi.org/ 10.1111/j.1365-2052.2005.01286.x.

50. Wang L, Xiong Y, Zuo B, Lei M, Ren Z, Xu D. Molecular and functional characterization of glycogen synthase in the porcine satellite cells under insulin treatment. Mol Cell Biochem. 2012; 360(1-2): 16980. https://doi.org/10.1007/s11010-011-1054-4.

51. Mir-Coll J, Duran J, Slebe F, Garcia-Rocha M, Gomis R, Gasa R, et al. Genetic models rule out a major role of beta cell glycogen in the control of glucose homeostasis. Diabetologia. 2016; 59(5): $1012-20$. https://doi.org/10.1007/s00125-016-3871-1.

52. ElGendy K, Malcomson FC, Lara JG, Bradburn DM, Mathers JC. Effects of dietary interventions on DNA methylation in adult humans: systematic review and meta-analysis. Br J Nutr. 2018; 120(9): 961-76. https://doi.org/10.1017/s000711451800243x.

\section{Figures}




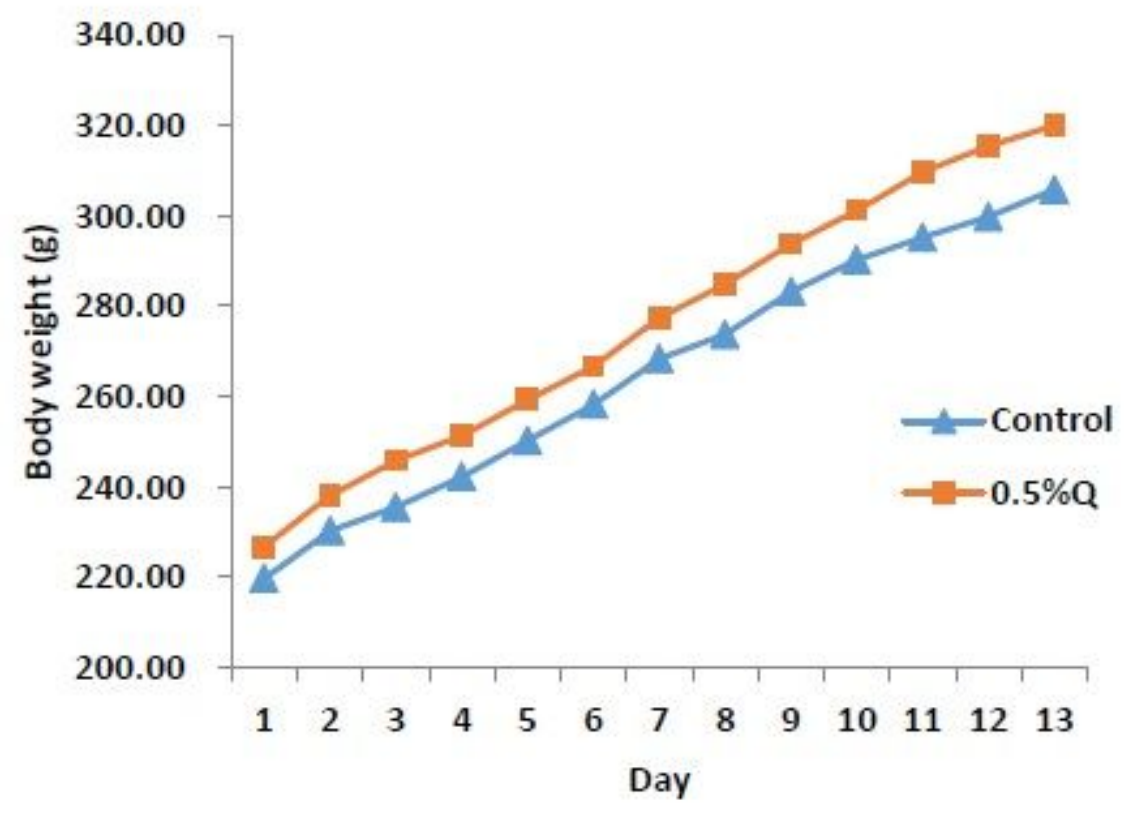

A

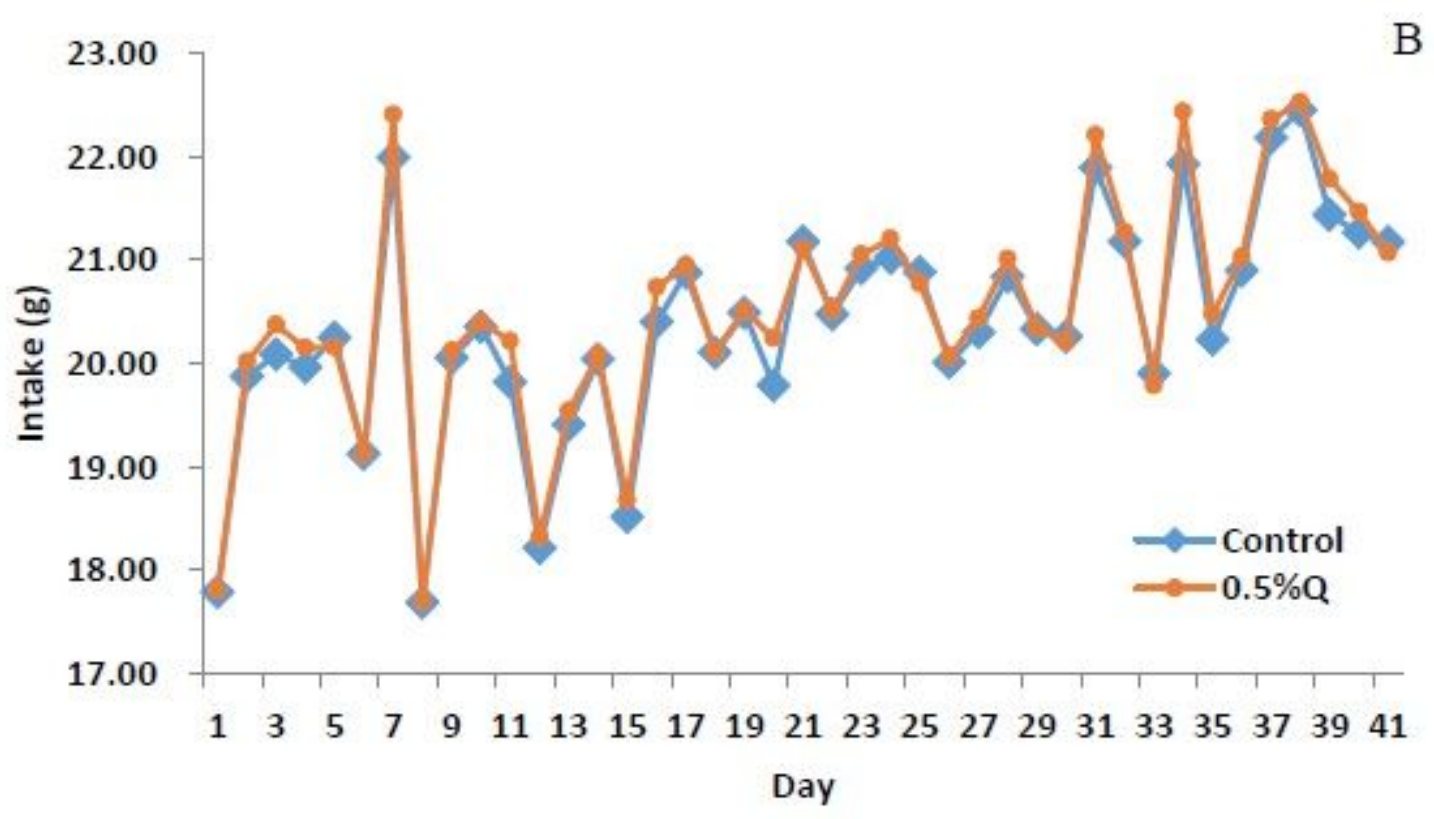

Figure 1

Changes of body weight and dietary intake during experimental period $( \pm s \rrbracket n=12)$. (A) Body weight change of rats; $(B)$ food intake change of rats. Wistar rats were fed with control and diet supplemented with $0.5 \%$ quercetin for 6 weeks. 


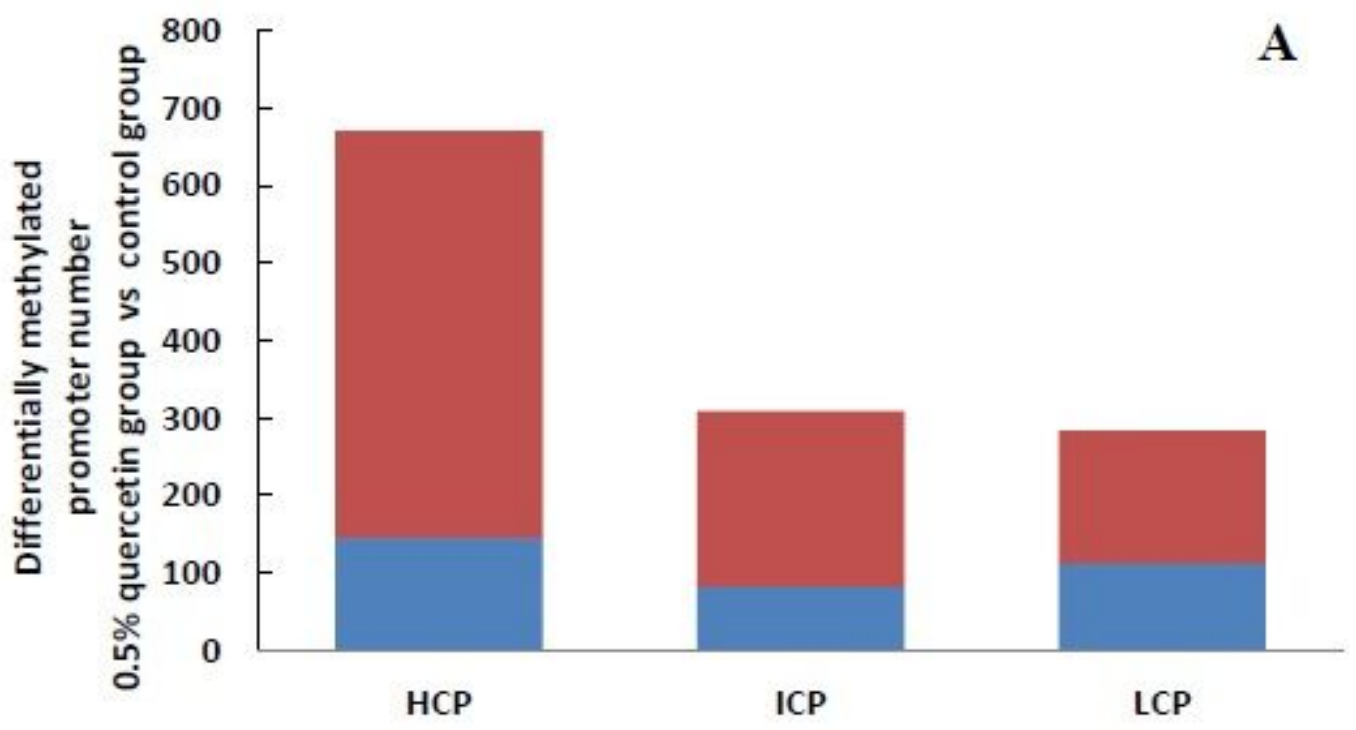

Hypomethylation Hypermethylation

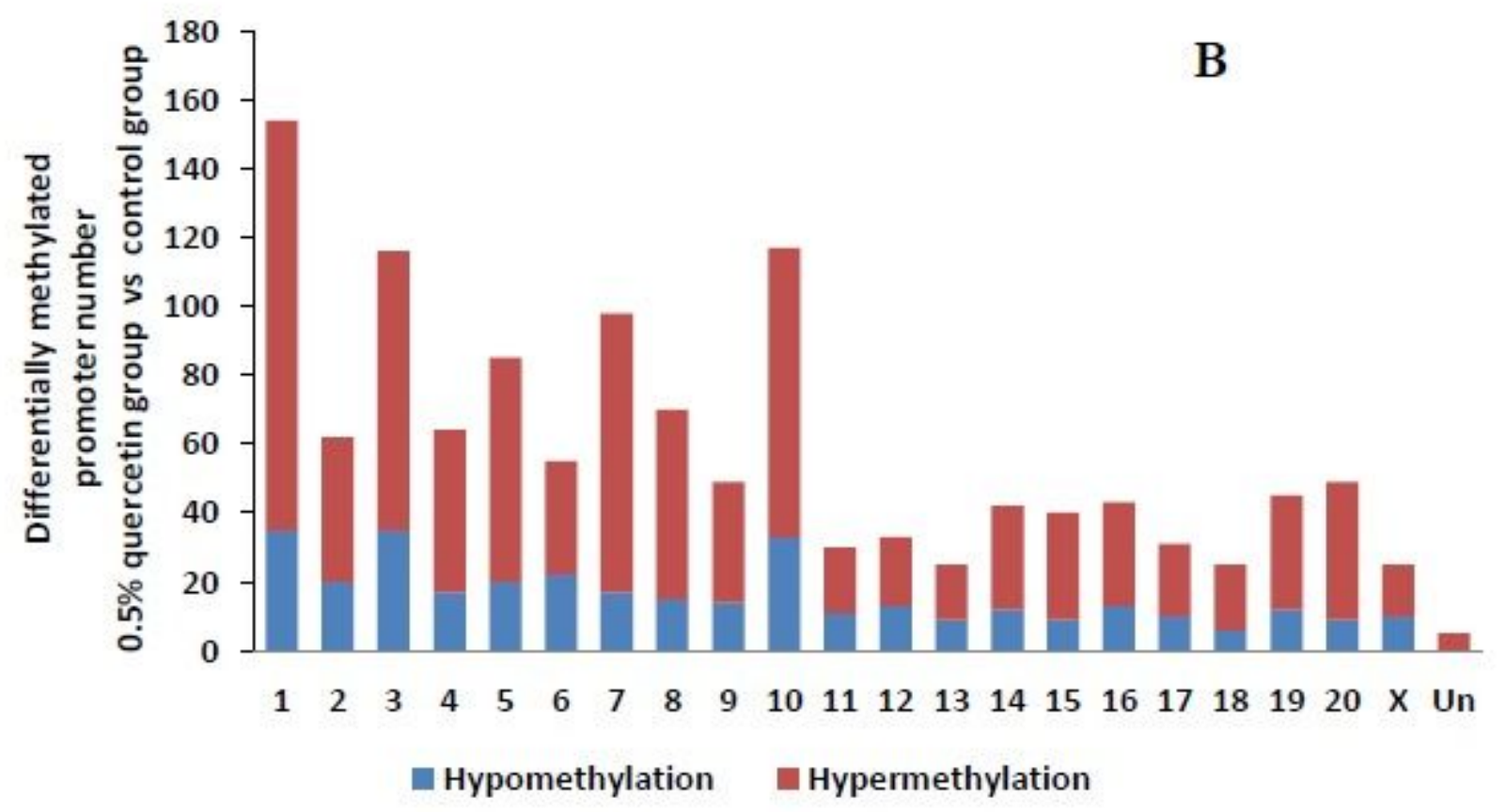

Figure 2

Differentially methylated promoters between $0.5 \%$ quercetin group and control group. (A) $\mathrm{CpG}$ density of differentially methylated promoters. (B) Chromosomal distribution of differentially methylated promoters. Blue, differentially hypomethylated promoters; red, differentially hypermethylated promoters. Classification of all promoters with high (HCP, high CpG density promoter), intermediated (ICP, intermediate CpG density promoter), and low (LCP, low CpG density promoter) CpG content. 


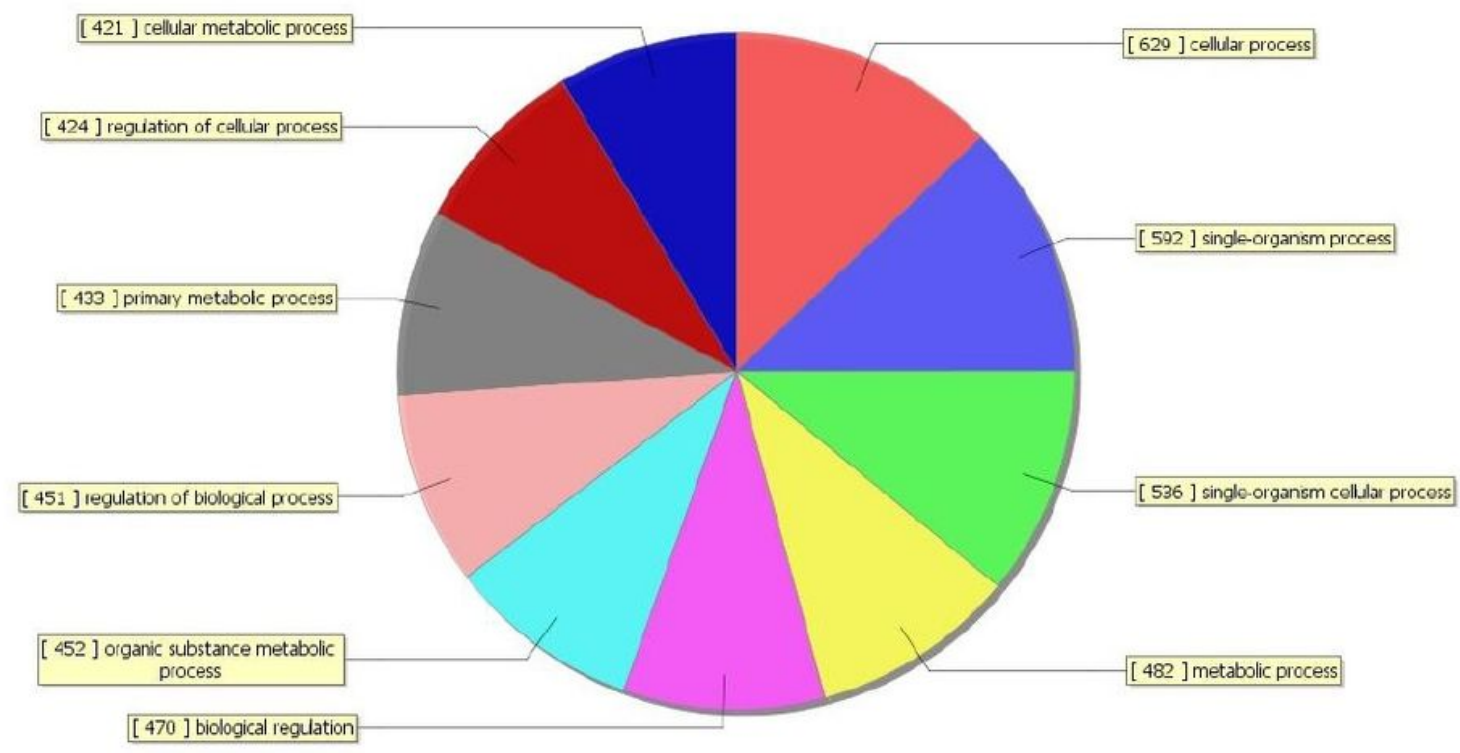

\section{Figure 3}

Quercetin group compared to control group of biological process up regulation of GO Biological Process Classification.

\section{GO Biological Process Classification}

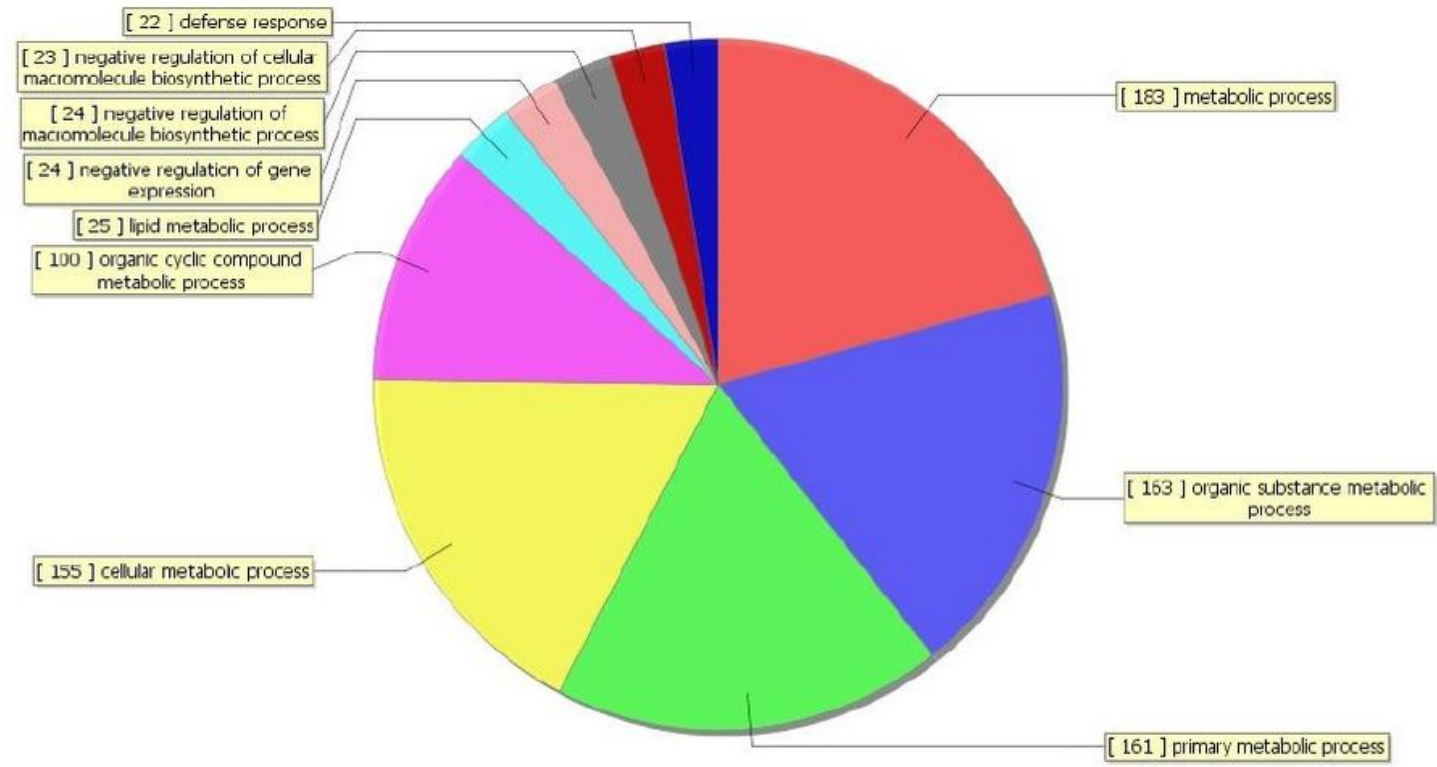

\section{Figure 4}


Quercetin group compared to control group of biological process down regulation of GO Biological Process Classification

\section{Sig pathway of DE gene}

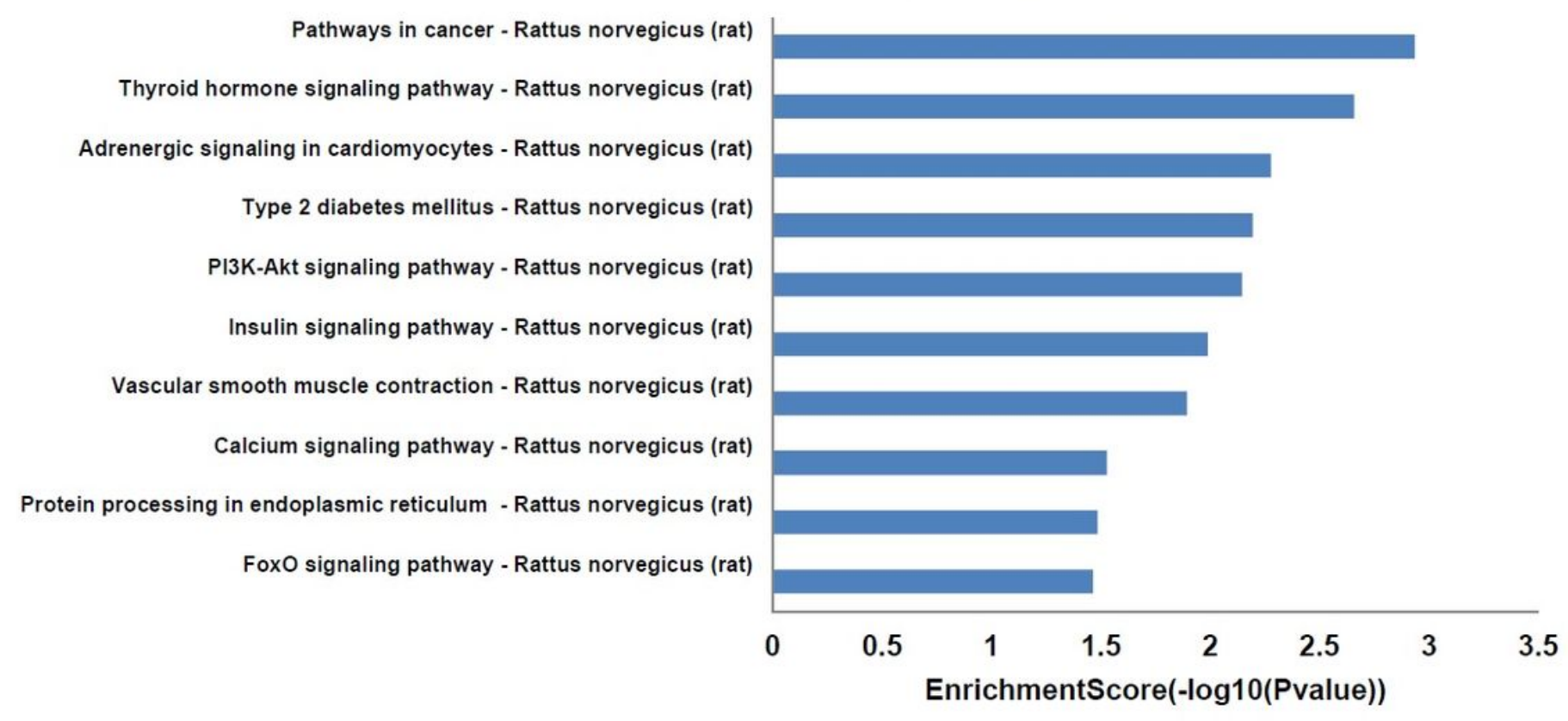

\section{Figure 5}

Quercetin group compared to control group of biological process up regulation of pathway analysis 
Flot1

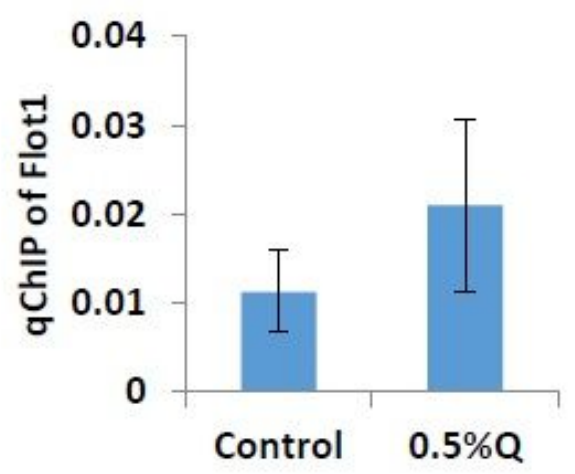

Gys1

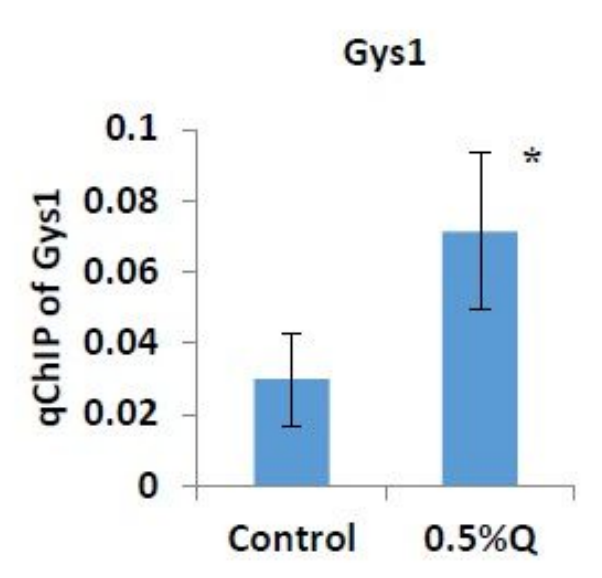

A

Flot1

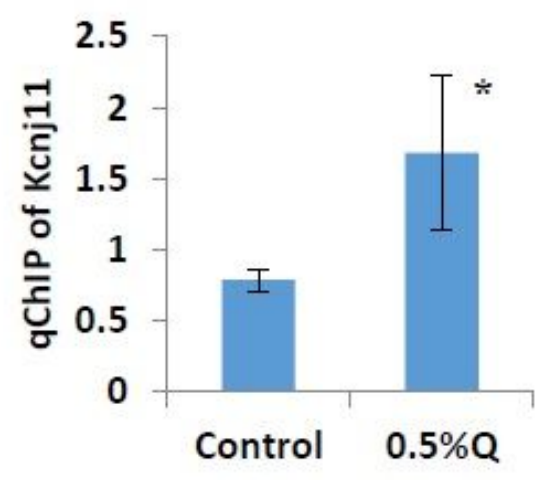

C

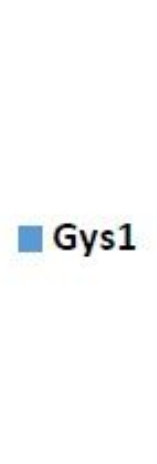

Kenj11

B

Kcnj11

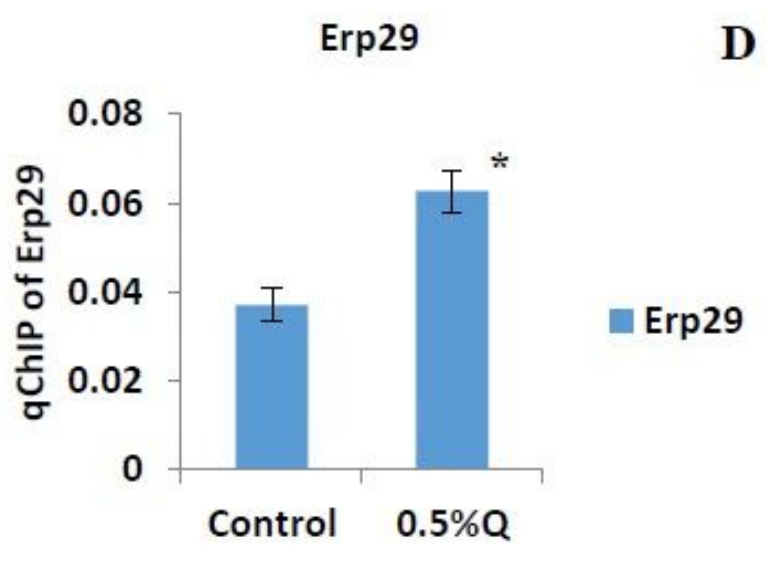

\section{Figure 6}

Quantitative ChIP results of differential genes. (A) Flot1; (B) Kcnj11; (C) Gys1; (D) Erp29. Data are expressed as the mean \pm SEM. Data with superscript letters $\left(^{*}\right)$ are significantly different at $p<0.05$ according to Student's t-test. Wistar rats were fed a AIN93M diet supplemented with or without quercetin for 6 weeks. 


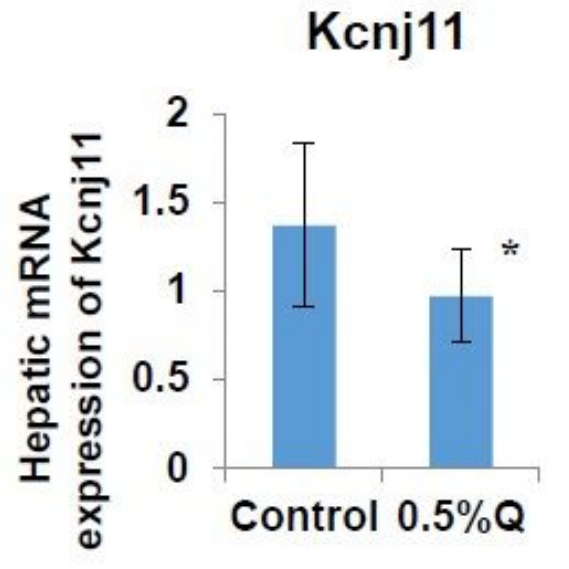

Erp9

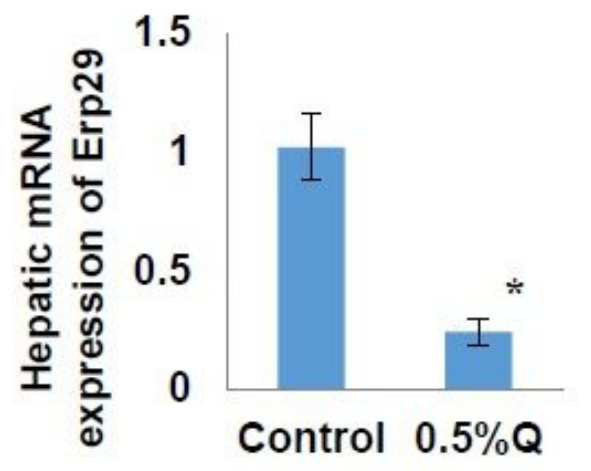

A

Kcnj11

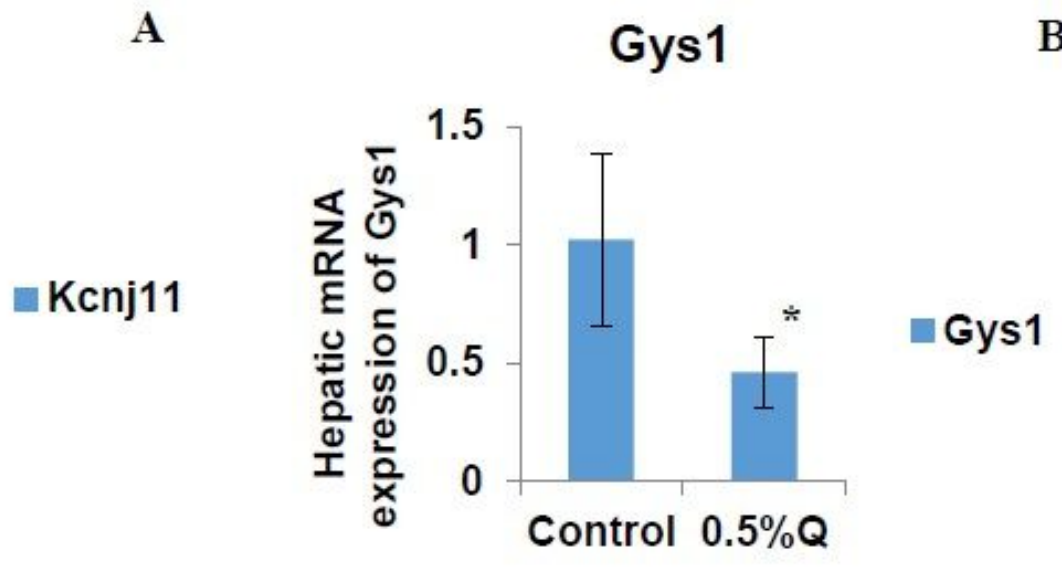

B

Erp9

Figure 7

Hepatic mRNA expression of Kcnj11, Erp29 and Gys1 in rats. (A) Kcnj11; (B) Erp29; (C) Gys1. Data are expressed as the mean \pm SEM. Data with superscript letters $(*)$ are significantly different at $p<0.05$ according to Student's t-test. Wistar rats were fed a AIN93M diet supplemented with or without quercetin for 6 weeks. 